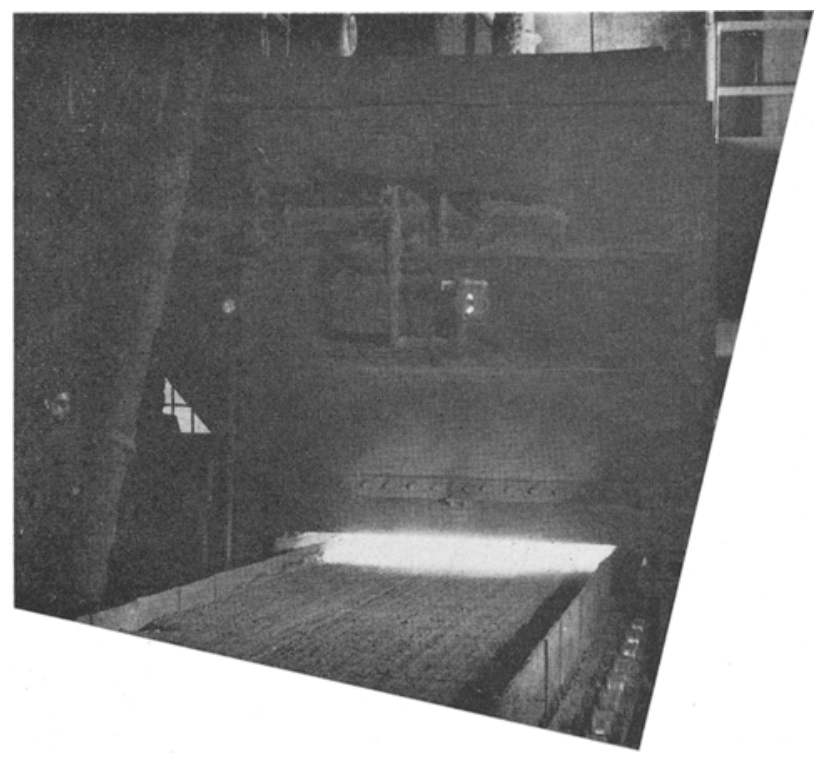

From

\title{
Established Sintering Techniques
}

\author{
... a new laboratory has been \\ designed to perfect and ex- \\ pand the scope of the sinter- \\ ing process.
}

The Dwight-Lloyd Div. of McDowell Co. has put into operation a complete mineral agglomeration laboratory and pilot plant with equipment for crushing, sizing and screening, pelletizing, heat-hardening pellets, sintering, blending of materials, strength analysis, and drying and calcining.

Currently under development is a disk agglomerator, or flying saucer, for agglomerating fines into a uniformly sized pellet for use in sintering. As the flying saucer revolves, the fines fed into the innermost saucer agglomerate. With increasing particle size, the pellets tumble over successive lips to the outer ring where they pass over the last lip and on to further processing.

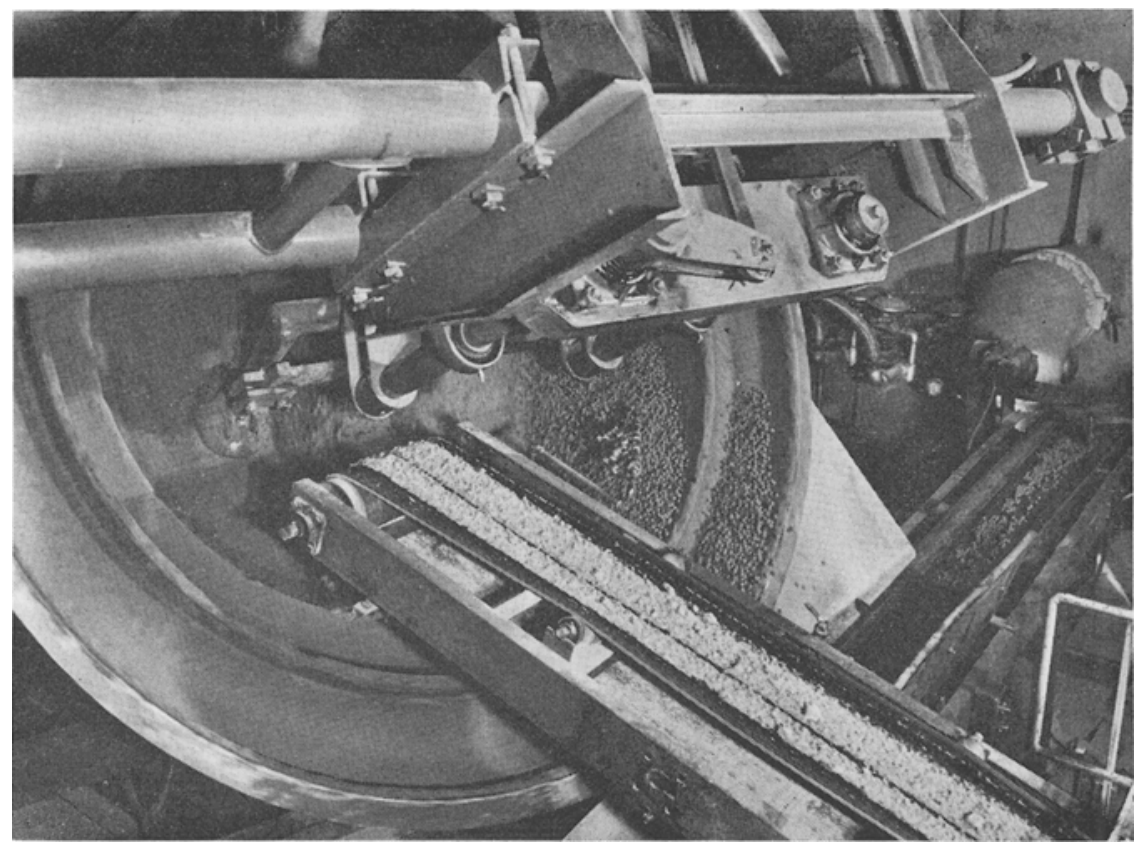

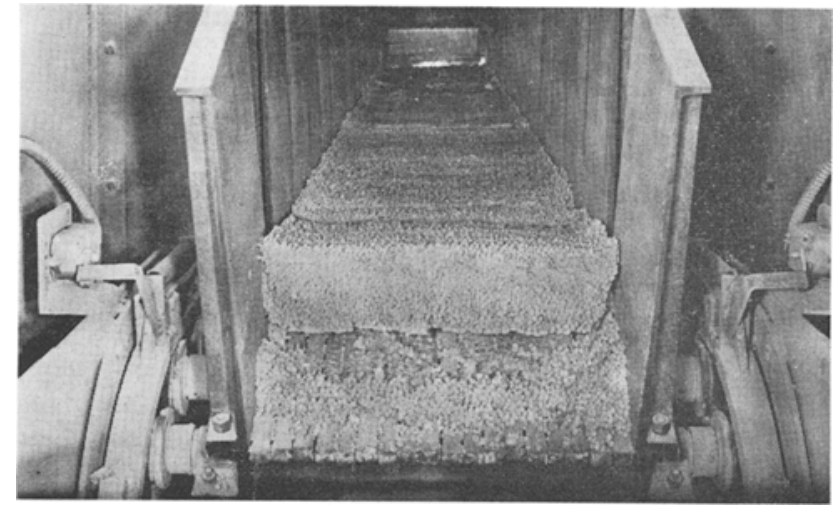

Also under development is equipment to use the up-draft principle of sintering. The sintering strand pictured at right is equipped for such experimentation.

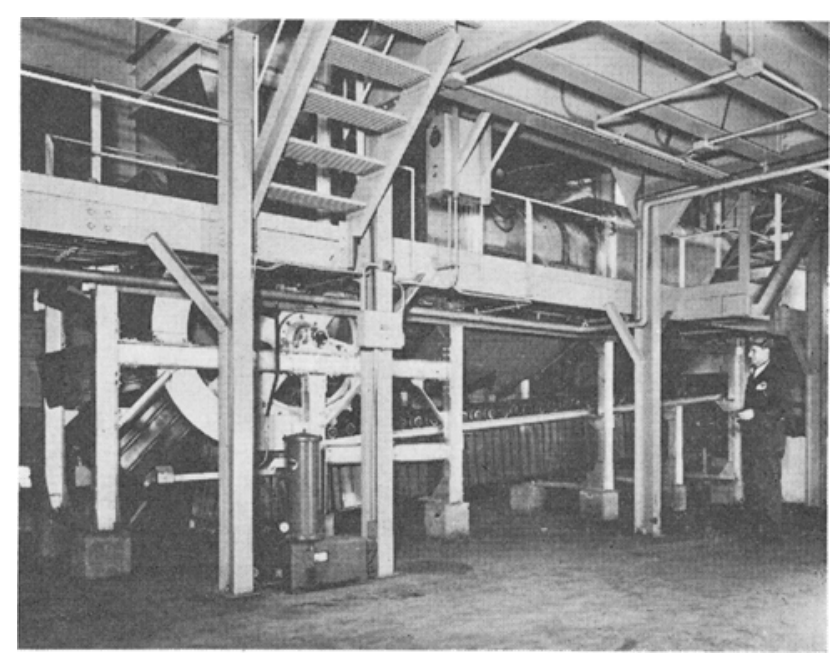

